\title{
ANALISIS PERBANDINGAN PRODUKTIVITAS PEKERJAAN FONDASI DANGKAL DENGAN MATERIAL BLOK BETON DAN PRODUKTIVITAS PEKERJAAN SESUAI SNI 2836:2008
}

\author{
Hari Nuryanto $^{1}$ dan Setya Winarno ${ }^{2, *}$ \\ ${ }^{1}$ Jurusan Teknik Sipil, Fakultas Teknik Sipil dan Perencanaan, Universitas Islam Indonesia \\ Email: 20934002@students.uii.ac.id \\ 2,*) Jurusan Teknik Sipil, Fakultas Teknik Sipil dan Perencanaan, Universitas Islam Indonesia \\ Email:winarno@uii.ac.id
}

\begin{abstract}
The use of concrete block material instead of rubble stone on shallow foundation work has many advantages. One aspect that needs to be studied is its workforce productivity. This paper aims to elaborate workforce productivity on shallow foundation work with concrete block material and compare its result to Standard of SNI 2836:2008. Data are collected from construction project which has site-wide construction in Krandon and site-narrow construction in Keringan. The method of data collection has been done by direct investigation from the beginning to the end of the foundation project and complemented by photo and video. These findings have shown that workforce productivity on shallow foundation work with concrete block material both in widesite and narrow site construction is higher than that of SNI Standards, i.e. 48,87\% and 7,14\% higher, respectively. Moreover, the productivity rate tends to increase due to the learning effect and adaptation on this foundation work done repetitively. There is a learning curve: $y=0,1271 \cdot \ln (x)+0,4818$, in which $y=$ productivity rate and $x=$ work session.
\end{abstract}

Keywords: productivity, shallow foundation, concrete block, SNI Standard

\section{PENDAHULUAN}

Pada umumnya, terdapat 5 (lima) sumber daya di dalam proyek yaitu manusia, material, peralatan, metode kerja, dan biaya. Husen (2009) mengungkapkan bahwa kelima sumber daya tersebut kemudian dihimpun dalam suatu wadah organisasi sementara untuk mencapai sasaran dan tujuan yang dapat didefinisikan sebagai proyek. Sasaran proyek konstruksi tidak dapat dipisahkan antara biaya, waktu, dan kualitas (Hinze, 2008). Fenomena keterikatan sasaran proyek tersebut misalnya adalah adanya penekanan biaya yang akan berimbas pada mutu yang berkurang, sedangkan waktu yang dipercepat akan berdampak pada biaya yang membengkak. Apabila salah satu aspek ditekan, maka akan mengakibatkan aspek yang lain menggelembung. Soekiman dkk. (2011) menggarisbawahi bahwa aspek waktu dapat diukur dari nilai produktivitas pekerjaan, sedangkan aspek produktivitas digaris bawahi oleh Ryu dkk. (2020). Pada saat yang sama, produktivitas yang tinggi akan menghasilkan nilai efisiensi waktu yang signifikan (Ravianto, 1986).

Saat ini, metode konstruksi pada suatu pekerjaan harus mempertimbangkan nilai produktivitas pekerjaan dengan seksama, sehubungan dengan permintaan jadwal yang singkat sesuai dengan keinginan dari pemilik proyek. Cara yang paling lazim untuk meningkatkan produktivitas pekerjaan adalah dengan mempersingkat tahapan pekerjaan. Semakin pendek sebuah tahapan pekerjaan dan kemudian pekerjaan tersebut dilakukan secara berulang-ulang, nilai produktivitas pekerjaan akan semakin meningkat (Olomalaiye dkk., 1998). Kinerja waktu

*) email korespondensi 
sebuah proyek dapat diukur dengan nilai produktivitasnya (Wong dkk., 2007).

Pada umumnya, material yang digunakan pada fondasi dangkal adalah batu belah atau batu alam yang direkatkan dengan plester (adukan pasir, semen, dan air) sehingga membentuk susunan material fondasi dangkal yang kompak dan padat. Batu belah ini diambil dari proses penambangan batu, yang biasanya berada di sekitar lereng gunung atau bukit batu. Batu belah dikirim ke lokasi proyek dalam dimensi yang bervariasi dari tempat penambangan. Diameter batu belah yang besar dapat mencapai $25 \mathrm{~cm}-35 \mathrm{~cm}$ dengan berat $50 \mathrm{~kg}-60 \mathrm{~kg}$. Selain permasalahan dengan dimensi, batu belah memiliki permukaan yang tidak beraturan. Dimensi dan bentuk permukaan batu belah yang tidak beraturan ini memerlukan luas lahan proyek yang memadai dalam penumpukannya dan tahapan pekerjaan pemasangan fondasi batu belah menjadi tidak mudah.

Produktivitas pekerjaan fondasi dengan batu belah di Balikpapan telah diteliti oleh Dahlia (2019). Hasil produktivitas untuk 1 orang tukang adalah sebesar $1,86 \mathrm{~m}^{3} /$ hari atau 0,267 $\mathrm{m}^{3} / \mathrm{jam}$. Dengan karakteristik batu belah yang demikian, tukang batu yang memasang fondasi batu belah ini akan memiliki metode kerja yang tidak sederhana. Hal ini terutama disebabkan oleh 4 hal yaitu (1) dimensi dan bentuk batu belah yang bervariasi menyebabkan tukang harus memilih dan memilah batu belah yang mana cocok untuk dipasang secara berurutan selanjutnya, (2) tukang atau pembantu tukang perlu memecah batu belah yang masih berdimensi besar agar mudah diangkat dan dipasang, (3) pembantu tukang perlu membuat plester pengikat (adukan semen, pasir, dan air) dengan volume yang banyak, dan (4) tukang perlu melakukan pekerjaan leveling dan perataan permukaan fondasi pada tahap akhir pekerjaan. Tahapan pekerjaan fondasi batu belah di atas cukup panjang sehingga berdampak pada produktivitas pekerjaan yang relatif rendah.
Untuk mempercepat produktivitas pekerjaan fondasi dangkal, tata cara konstruksi yang panjang tersebut di atas harus dipangkas untuk memperoleh efisiensi sumber daya (Kedir dan Hall, 2021). Untuk itu, Nuryanto dan Winarno (2021) telah melakukan penggantian material fondasi dangkal dari batu belah (yang sudah lazim dipakai) dengan material blok beton. Dimensi blok beton dibuat seragam dan berbentuk persegi dengan ukuran $40 \quad \mathrm{~cm} \quad$ x $22 \quad \mathrm{~cm} \quad \mathrm{x} \quad 12 \mathrm{~cm}$. Permukaannya dibuat kasar agar memiliki kemampuan lekatan yang baik dengan plester pengikatnya. Material blok beton dibuat secara pabrikasi dengan campuran semen, pasir, kerikil, dan batu.

Material blok beton untuk fondasi dangkal ini telah diaplikasikan pada pekerjaan fondasi pagar yang lurus dengan lahan yang luas di Krandon, Wedomartani, Ngemplak, Sleman. Produktivitas kerja pada pekerjaan di Krandon ini telah diamati dan diukur oleh Nuryanto dan Winarno (2021), dimana 1 orang tukang batu rata-rata memiliki produktivitas kerja sebesar $0,396 \mathrm{~m}^{3} / \mathrm{jam}$.

Dalam SNI 2836-2008 tentang Tata Cara Perhitungan Harga Satuan Pekerjaan Fondasi untuk Konstruksi Bangunan Gedung dan Perumahan, standar produktivitas pekerjaan fondasi batu adalah 1 orang tukang batu yang memiliki produktivitas rata-rata sebesar 0,266 $\mathrm{m}^{3} / \mathrm{jam}$. Standar SNI ini bersifat umum dengan tanpa mencantumkan kondisi lahan yang luas atau sempit, serta denah fondasi yang lurus atau berbelok-belok. Pada kasus pekerjaan fondasi di Krandon dengan lahan yang luas dan denah yang lurus di atas, nilai produktivitas kerjanya lebih besar 0,13 $\mathrm{m}^{3} /$ jam dibandingkan Standar SNI.

Sehubungan dengan produktivitas pekerjaan fondasi blok beton di lahan yang luas dengan denah yang lurus memanjang sudah dilakukan di Krandon, produktivitas pekerjaan di lahan yang sempit perlu dikaji lebih mendalam untuk melengkapi gambaran produktivitas pekerjaan fondasi dangkal dengan material blok beton secara menyeluruh. Artikel ini akan menguraikan hasil investigasi tentang 
produktivitas pembangunan fondasi rumah tinggal ukuran $6 \mathrm{~m} \times 7 \mathrm{~m}$ dengan material blok beton di Dusun Keringan, Kecamatan Turi, Sleman dengan lahan yang sempit dan denahnya berbelok-belok. Denah fondasi rumah memiliki panjang sekitar $34,5 \mathrm{~m}$, tidak memanjang seperti pagar, dan di lahan yang relatif sempit. Tukang dan pembantu tukang yang melaksanakan pekerjaan ini adalah personil yang sama pada pekerjaan pagar di Krandon. Penelitian ini merupakan kelanjutan dari penelitian sebelumnya (Nuryanto \& Winarno, 2021). Hasil investigasi ini ini akan merangkum dan mengkompilasi produktivitas pekerjaan fondasi blok beton di lahan yang luas di Krandon dan lahan yang sempit di Keringan, yang kemudian hasilnya akan dibandingkan dengan Standar SNI 2836:2008.

\section{METODE PENELITIAN}

Penelitian ini merupakan kelanjutan dari penelitian sebelumnya dan data primer pada penelitian ini dikumpulkan dari pembangunan fondasi rumah tinggal di Keringan, Kec. Turi, Kabupaten Sleman, Daerah Istimewa Yogyakarta. Ukuran rumah adalah $6 \mathrm{~m} \mathrm{x} 7 \mathrm{~m}$, dan denah fondasi rumah memiliki panjang sekitar 34,5 m, denahnya berbelok belok, dan di lahan yang relatif sempit. Pekerjaan galian dan urugan tanah tidak dimasukkan dalam kajian ini.

Terdapat 2 tukang dan 3 orang pekerja yang melaksanakan pekerjaan ini dan personil ini adalah personil yang sama dengan penelitian sebelumnya. Selain personil tukang, variabel yang sama adalah ukuran blok beton, metode kerja, dan campuran adukan plesternya.

Data primer dikumpulkan melalui pencatatan, perekaman foto dan video, serta diskusi dengan personil di lokasi. Investigasi ini dilakukan langsung dengan detail dari awal sampai dengan semua pekerjaan selesai. Data yang diperoleh adalah capaian volume pekerjaan dan waktu yang dibutuhkan secara langsung dari awal sampai akhir pekerjaan. Waktu yang diukur adalah waktu efektif saat tukang bekerja, sehingga waktu istirahat dan jeda waktu karena gangguan oleh aktivitas yang lain atau karena gangguan cuaca tidak dimasukkan sebagai data. Pekerjaan galian dan urugan tanah tidak dimasukkan dalam analisis. Data yang telah dikumpulkan kemudian dikompilasi dengan data dari Nuryanto dan Winarno (2021) dan kemudian dibandingkan dengan SNI 2836-2008. Data ini diolah dengan bantuan MS Excel melalui metode regresi yang relevan.

\section{MATERIAL BLOK BETON}

Sebagaimana diuraikan di atas, pemakaian material batu belah untuk pekerjaan fondasi dangkal memiliki 4 kelemahan utama. Pada tahapan awal, tukang perlu memilih dan memilah batu belah yang cocok untuk dipasang agar susunan batu belah memiliki rongga antar batu belah yang minimal, sehingga diperoleh susunan struktur fondasi dangkal yang kompak dan padat. Permukaan batu belah adalah tidak beraturan sehingga membutuhkan plester pengikat yang banyak dengan ketebalan plester yang bervariasi dan dapat mencapai tebal $8 \mathrm{~cm}-10 \mathrm{~cm}$. Dengan metode ini, dibutuhkan banyak semen, pasir, dan air. Selain itu, waktu pencampuran serta pemasangannya pun juga relatif lama.

Kelemahan penggunaan batu belah di atas dapat diatasi dengan pemakaian material blok beton. Nuryanto dan Winarno (2021) telah mencoba mengaplikasikan material blok beton ini pada pekerjaan fondasi dangkal. Ukuran blok beton adalah seragam, yaitu 12 $\mathrm{cm} \times 22 \mathrm{~cm}$ x $40 \mathrm{~cm}$ yang dipabrikasi di Pusat Inovasi Material Vulkanis Merapi, Universitas Islam Indonesia (PIMVM UII). Tipikal ukuran ini sama dengan ukuran blok beton dengan agregat sekam padi (Pramono dkk., 2020)

Permukaan blok beton dibuat kasar agar dapat melekat dengan plester pengikatnya secara baik. Material tersebut dibuat dengan campuran semen, pasir, kerikil, dan batu. Agregat batu pada material tersebut memiliki diameter yang bervariasi antara $5 \mathrm{~cm}-10 \mathrm{~cm}$. 
Ketebalan plester pengisi fondasi blok beton rata-rata adalah $1 \mathrm{~cm}$, dengan perbandingan campuran plester 1 semen : 2 pasir : 2 abu batu. Kelebihan dari blok beton ini adalah dapat dibuat secara pabrikasi, kebutuhan plester perekat dapat dikurangi, tidak memerlukan tempat penempatan yang luas di lokasi proyek, waktu pemasangan yang lebih cepat, dan material sisa sangat kecil.

Material blok beton untuk fondasi dangkal ini telah diaplikasikan pada pekerjaan fondasi pagar sepanjang 66,7 m di Krandon, Wedomartani, Ngemplak, Sleman. Pekerjaan fondasi pagar di atas memiliki denah yang lurus, memanjang, dan lahannya luas. Produktivitas kerja pada pekerjaan di Krandon ini telah diamati dan diukur oleh Nuryanto dan Winarno (2021), dimana 1 orang tukang batu rata-rata memiliki produktivitas kerja sebesar $0,396 \mathrm{~m}^{3} / \mathrm{jam}$. Pada kasus yang lain, Bao dan Li (2020) telah mencoba mengaplikasikan blok beton dengan sambungan antar blok beton menggunakan sistem lego.

\section{FONDASI RUMAH TINGGAL}

Rumah tinggal yang dikaji memiliki denah fondasi seperti di Gambar 1 sebagai berikut. Panjang fondasi adalah sekitar 34,5 m.

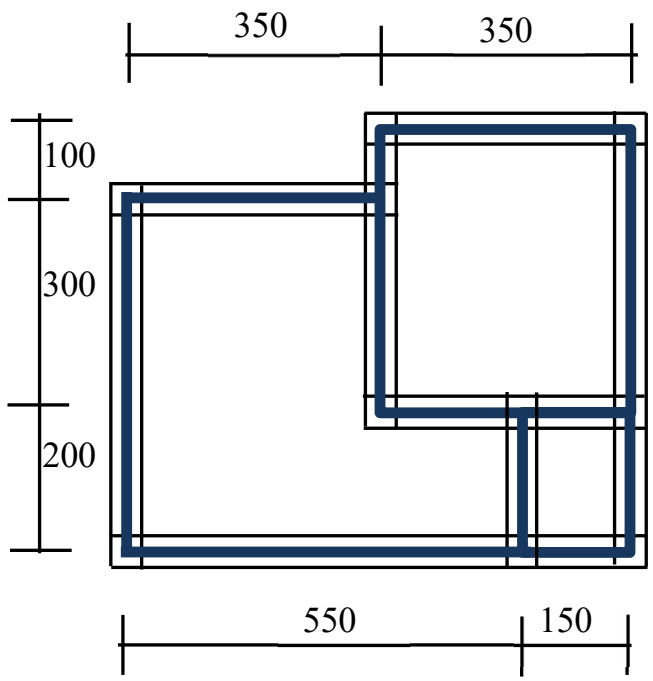

Gambar 1. Denah fondasi rumah tinggal
Adapun skema potongan pondasi dengan material blok beton adalah disajikan dalam Gambar 2. Luas penampang atau potongan fondasi pada Gambar 2 adalah $0,011 \mathrm{~m}^{2}$. Volume pekerjaan fondasi dapat dihitung melalui perkalian antara luas penampang dan panjang fondasinya, yaitu $0,011 \mathrm{~m}^{2} \times 34,5 \mathrm{~m}$ $=0,39 \mathrm{~m}^{3}$.

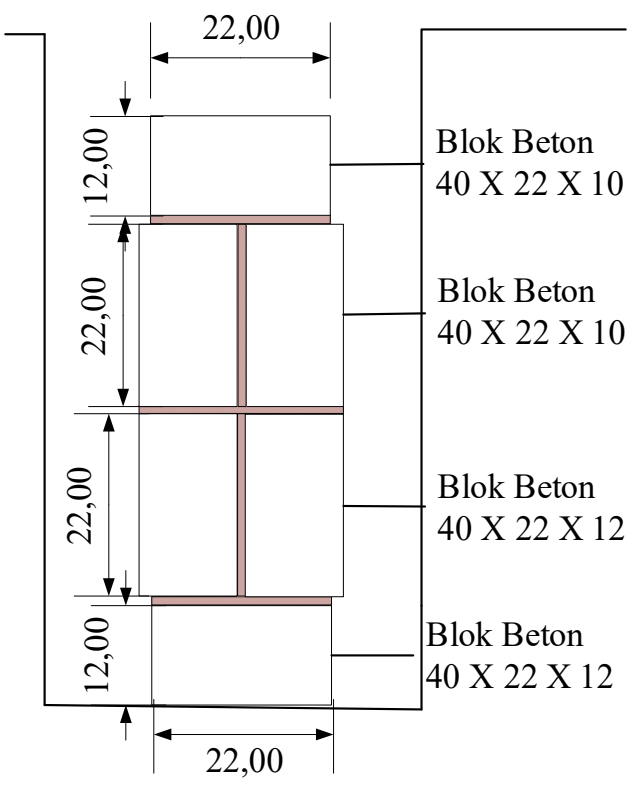

Gambar 2. Potongan fondasi blok beton

\section{STANDAR SNI 2836: 2008}

Standar SNI 2836: 2008 ini menguraikan tata cara perhitungan harga satuan pekerjaan pondasi batu belah untuk bangunan sederhana. Nilai produktivitas dalam standar ini dirangkum dari dokumen proyek-proyek di beberapa BUMN, kontraktor, serta analisis BOW. Data kemudian dilengkapi dengan penelitian lapangan sebagai cross check pada tahap sebelumnya, yang berupa penelitian produktivitas tenaga kerja lapangan pada beberapa proyek pembangunan gedung dan perumahan serta penelitian laboratorium bahan bangunan untuk komposisi bahan yang digunakan pada setiap jenis pekerjaan dengan pendekatan kinerja dari jenis pekerjaan terkait.

Standar ini menetapkan indeks bahan bangunan dan indeks tenaga kerja yang 
dibutuhkan untuk tiap satuan pekerjaan pondasi yang dapat dijadikan acuan dasar yang seragam bagi para pelaksana pembangunan gedung dan perumahan dalam menghitung besarnya harga satuan pekerjaan pondasi untuk bangunan gedung dan perumahan.

Perhitungan indeks bahan telah ditambahkan toleransi sebesar 5\%-20\%, dimana di dalamnya termasuk angka susut, yang besarnya tergantung dari jenis bahan dan komposisi adukan. Jam kerja efektif untuk tenaga kerja diperhitungkan adalah 5 jam per hari.

Standar ini mengatur bahwa 1 orang tukang akan dibantu oleh 2 orang pekerja. Satu orang tukang batu memiliki koefisien produktivitas sebesar 0,75 orang/hari untuk $1 \mathrm{~m}^{3}$ pekerjaan pondasi batu belah, atau $1: 0,75=1,33$ $\mathrm{m}^{3} /$ hari. Dalam Standar SNI, jam kerja efektif adalah 5 jam per hari, sehingga produktivitas 1 orang tukang adalah $1,33: 5=0,266 \mathrm{~m}^{3} / \mathrm{jam}$.

\section{DATA DAN ANALISIS}

\section{Data Produktivitas Kerja di Lahan yang Lapang}

Data ini merupakan data sekunder yang telah dikumpulkan oleh Nuryanto dan Winarno (2021). Pekerjaan fondasi blok beton di Krandon, Wedomartani, Ngemplak, Sleman adalah berupa fondasi pagar sepanjang 66,7 $\mathrm{m}$, memiliki denah yang lurus, dan lahannya luas. Pekerjaan fondasi dibagi menjadi Tahap I di sisi Utara dan Tahap II di sisi Selatan.
Pekerjaan ini dilaksanakan oleh 2 tukang dan 3 orang pekerja. Tabel 1 menyajikan produktivitas kerja rata-rata adalah 0,7925 $\mathrm{m}^{3} / \mathrm{jam}$ untuk 2 orang tukang, sehingga 1 orang tukang batu rata-rata memiliki produktivitas kerja sebesar $0,396 \mathrm{~m}^{3} / \mathrm{jam}$.

\section{Data Produktivitas di Lahan yang Sempit}

Data ini merupakan data primer yang dikumpulkan dari pengamatan langsung pembangunan fondasi blok beton rumah tinggal ukuran $7 \mathrm{~m}$ x $6 \mathrm{~m}$ di Keringan, Wonokerto, Kecamatan Turi, Kabupaten Sleman (lihat Gambar 1). Pekerjaan fondasi ini adalah sepanjang $35,5 \mathrm{~m}$, memiliki denah yang berbelok-belok, dan lahannya sempit. Pekerjaan ini dilaksanakan oleh personil yang sama dengan yang mengerjakan di Krandon, yaitu 2 tukang dan 3 orang pekerja. Selain personil tukang yang sama: ukuran blok beton, metode kerja, dan campuran adukan plester juga dibuat sama. Waktu yang diperlukan untuk mengerjakan keseluruhan fondasi ini dari awal sampai dengan akhir adalah 2 hari, yang kemudian dibagi dalam 4 sesi pekerjaan. Dalam waktu 2 hari: semua pekerjaan fondasi sudah selesai $100 \%$, sehingga tidak ada pengamatan di hari ketiga dan seterusnya. Jadi waktu pengamatan selama 2 hari tersebut sudah final dan tidak ada data lagi setelah itu. Tabel 2 menyajikan 4 sesi pekerjaan dengan produktivitas kerja rata-rata adalah 0,5702 $\mathrm{m}^{3} /$ jam untuk 2 orang tukang batu, sehingga 1 orang tukang rata-rata memiliki produktivitas kerja sebesar $0,285 \mathrm{~m}^{3} / \mathrm{jam}$.

Tabel 1. Hasil pengukuran produktivitas pekerjaan pondasi di lahan yang lapang

(Nuryanto dan Winarno, 2021)

\begin{tabular}{|l|c|c|c|}
\hline & $\begin{array}{c}\text { Durasi } \\
(\text { jam })\end{array}$ & $\begin{array}{c}\text { Volume } \\
\left(\mathrm{m}^{3}\right)\end{array}$ & $\begin{array}{c}\text { Produktivitas } \\
\left(\mathrm{m}^{3} / \mathrm{jam}\right)\end{array}$ \\
\cline { 2 - 4 } & $(1)$ & $(2)$ & $(3)=(2) /(1)$ \\
\hline Tahap I & 7,250 & 5,522 & 0,753 \\
\hline Tahap II & 17,400 & 14,479 & 0,832 \\
\hline \multicolumn{2}{l}{ Rata-rata produktivitas untuk 2 tukang } & 0,7925 \\
\hline \multicolumn{2}{l}{ Rata-rata produktivitas untuk 1 tukang } & 0,396 \\
\hline
\end{tabular}


Tabel 2. Hasil pengukuran produktivitas pekerjaan pondasi di lahan yang sempit

\begin{tabular}{|c|c|c|c|c|c|c|}
\hline & \multirow[t]{2}{*}{ Sesi } & Mulai & Selesai & $\begin{array}{c}\text { Durasi } \\
\text { (jam) }\end{array}$ & $\begin{array}{c}\text { Volume } \\
\left(\mathrm{m}^{3}\right)\end{array}$ & $\begin{array}{l}\text { Produktivitas } \\
\left(\mathrm{m}^{3} / \mathrm{jam}\right)\end{array}$ \\
\hline & & (1) & (2) & (3) & (4) & $(5)=(4) /(3)$ \\
\hline \multirow{2}{*}{ Hari 1} & 1. Pagi & $08: 15$ & $12: 00$ & 3,75 & 1,804 & 0,481 \\
\hline & 2. $\quad$ Siang & 13:05 & $14: 05$ & 1,00 & 0,572 & 0,572 \\
\hline \multirow{2}{*}{ Hari 2} & 3. Pagi & 08:00 & $12: 00$ & 4,00 & 2,482 & 0,620 \\
\hline & 4. Siang & $13: 00$ & $14: 30$ & 1,50 & 0,987 & 0,658 \\
\hline \multicolumn{4}{|c|}{ Total } & 10,25 & 5,844 & \\
\hline \multicolumn{6}{|c|}{ Rata-rata produktivitas untuk 2 tukang } & 0,5702 \\
\hline \multicolumn{6}{|c|}{ Rata-rata produktivitas untuk 1 tukang } & 0,285 \\
\hline
\end{tabular}

Sesuai dengan Tabel 1, produktivitas kerja pada pekerjaan fondasi dangkal dengan material blok beton pada lokasi yang lapang adalah sebesar $0,396 \mathrm{~m}^{3} / \mathrm{jam}$, sedangkan Tabel 2 menyajikan produktivitas di lahan yang sempit adalah sebesar $0,285 \mathrm{~m}^{3} / \mathrm{jam}$. Sementara itu, produktivitas kerja sesuai dengan Standar SNI 2836:2008 adalah sebesar $0,266 \mathrm{~m}^{3} / \mathrm{jam}$. Penelitian Dahlia (2019) menghasilkan produktivitas sebesar $2,67 \mathrm{~m}^{3} / \mathrm{jam}$. Produktivitas di lahan lapang, di lahan sempit, dan produktivitas sesuai dengan Standar SNI tersebut dapat disajikan dalam diagram seperti di Gambar 3.

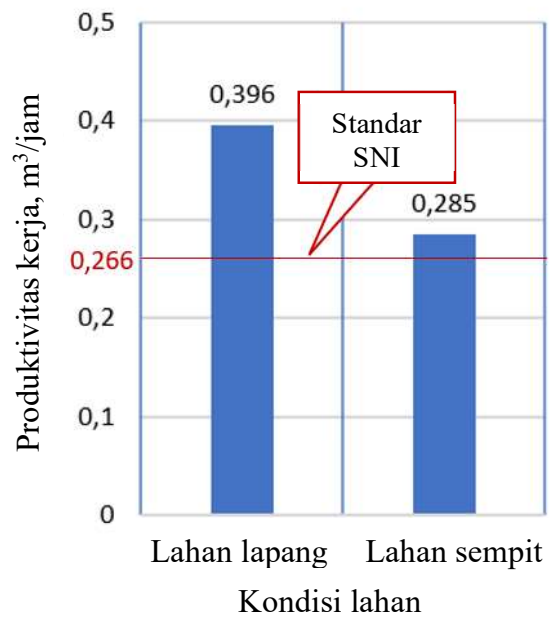

Gambar 3. Nilai produktivitas pekerjaan di lahan lapang, di lahan sempit, dan produktivitas sesuai Standar SNI

\section{PEMBAHASAN}

Penggunaan material blok beton untuk fondasi dangkal memiliki banyak keuntungan dibandingkan dengan material batu belah. Secara garis besar, keuntungan penggunaan material blok beton ini adalah sebagai berikut.

a. Berbentuk persegi panjang dan dapat dicetak di pabrik secara massal,

b. Susunan fondasi dengan material blok beton dapat dibuat rapi dan teratur sehingga kebutuhan mortar perekat menjadi sedikit,

c. Material blok beton dapat ditumpuk secara rapi dan teratur sehingga menghemat lokasi proyek,

d. Karena semua bentuknya seragam, maka tukang dapat langsung memasang material blok beton dan tidak perlu memilih atau memilah sebelumnya, sehingga waktu pemasangan menjadi yang lebih cepat.

e. Kebutuhan material blok beton dapat dihitung dengan tepat pada saat perencanaan, sehingga material sisa dapat diminimalkan.

Produktivitas pekerjaan secara nyata, baik untuk lahan yang lapang maupun sempit, memiliki nilai produktivitas yang lebih besar dari pada Standar SNI. Pada lahan yang lapang produktivitas yang lebih tinggi dibandingkan dengan Standar SNI, yaitu lebih besar $48,87 \%$, sedangkan di lahan sempit hanya lebih besar $7,14 \%$. 
Pada Tabel 1 dan Tabel 2, nilai produktivitas pekerjaan di saat awal pekerjaan masih kecil karena personilnya baru mulai belajar memasang material pondasi pada tahap permulaan. Setelah terjadi pengulangan pekerjaan, tukang dan pekerja mulai terlatih dan terampil sehingga tampak nilai produktivitas pekerjaan meningkat karena adanya proses pembelajaran atau adaptasi pada pekerjaan yang sama dan berulang. Peningkatan produktivitas juga berimplikasi pada waktu pengerjaan yang cepat sehingga biaya upah pekerja dapat ditekan. Gambar 4 menguraikan peningkatan produktivitas pada pekerjaan fondasi blok beton di Keringan sesuai Tabel 2. Tren peningkatan produktivitas juga terjadi di Krandon (Nuryanto dan Winarno, 2021).

Temuan dalam penelitian ini adalah bahwa pemakaian blok beton telah memenuhi Standar SNI 2836:2008, baik untuk lahan lokasi proyek yang lapang maupun sempit.
Pemenuhan Standar SNI ini akan menjadi lebih baik karena telah terjadi proses belajar pada pelaksanaan pekerjaan fondasi blok beton, yang mana nilai produktivitas meningkat seiring dengan proses adaptasi pekerjaan. Adapun persamaan regresinya adalah $y=0,1271 \cdot \ln (x)+0,4818$, dimana $y$ adalah produktivitas pekerjaan dan $x$ adalah nomor urutan sesi pekerjaan.

Terkait dengan tingkat kesiapan teknologi (yang merupakan indikator seberapa siap atau matang suatu teknologi yang dimiliki dapat diaplikasikan atau diterapkan oleh pengguna atau calon pengguna teknologi), penelitian ini merupakan demonstrasi prototipe material blok beton untuk fondasi di lingkungan sebenarnya. Demonstrasi pada sistem nyata ini adalah berupa aplikasi fondasi blok beton untuk fondasi dangkal di Keringan dan Krandon, yang dapat dikategorikan dalam TKT (Tingkat Kesiapan Tekologi) Level 7.

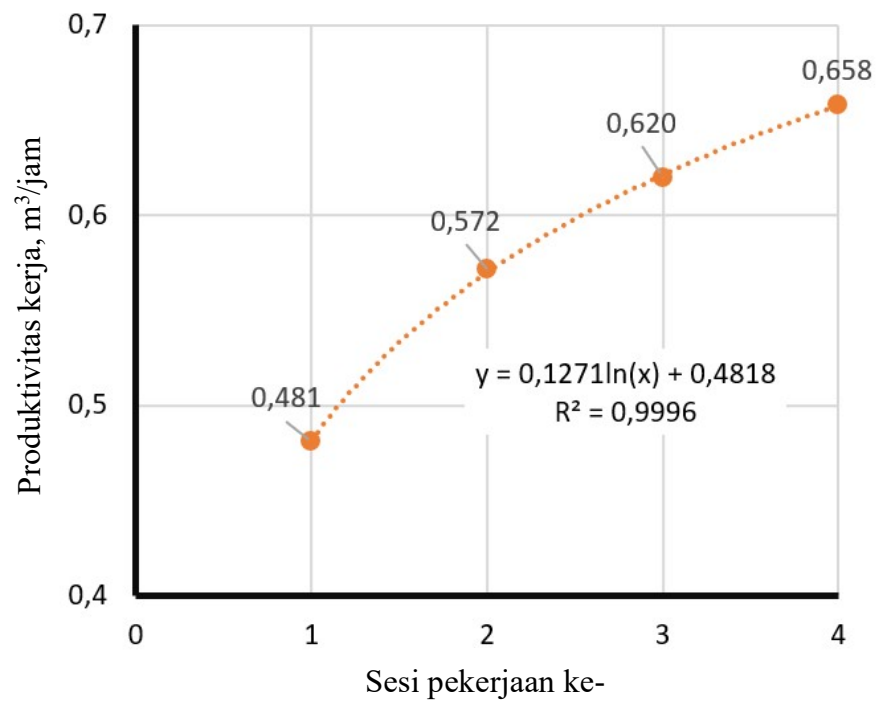

Gambar 4. Peningkatan produktivitas pekerjaan fondasi blok beton

\section{KESIMPULAN}

Pemakaian material blok beton pada pekerjaan fondasi dangkal memiliki banyak kelebihan dibandingkan dengan penggunaan material batu belah. Produktivitas pekerjaan fondasi dangkal dengan material blok beton baik untuk lahan proyek yang lapang maupun sempit dapat memenuhi Standar SNI 2836:2008 tentang Tata Cara Perhitungan Harga Satuan Pekerjaan Pondasi Batu Belah untuk Bangunan Sederhana. Produktivitas 
nyata pada lahan yang luas dan sempit adalah lebih besar dibandingkan dengan Standar SNI, yaitu lebih besar $48,87 \%$ dan $7,14 \%$ masing-masing. Produktivitas nyata yang terjadi menjadi lebih besar karena telah terjadi proses belajar dan adaptasi pada pekerjaan yang berulang ini. Kurva belajar yang terjadi pada lahan yang sempit memiliki persamaan $\mathrm{y}=0,1271 \cdot \ln (\mathrm{x})+0,4818$, dimana $y$ adalah produktivitas pekerjaan dan $x$ adalah nomor urutan sesi pekerjaan.

\section{UCAPAN TERIMA KASIH}

Inovasi dalam penelitian merupakan bukti kesungguhan usaha tim di Pusat Inovasi Material Vulkanis Merapi (PIMVM), Universitas Islam Indonesia (UII). Penulis mengucapkan banyak terima kasih kepada Jurusan Teknik Sipil dan Program Doktor Teknik Sipil UII, serta para personil di proyek Krandon dan Keringan yang telah banyak memberi bantuan dan dukungannya.

\section{DAFTAR PUSTAKA}

Badan Standarisasi Nasional. (2008). "SNI 2836-2008 tentang Tata Cara Perhitungan Harga Satuan Pekerjaan Fondasi untuk Konstruksi Bangunan Gedung dan Perumahan". Jakarta.

Bao, Y., dan Li, V.C. (2020). "Feasibility Study of Lego-inspired Construction with Bendable Concrete". Automation in Construction, 113. 103161.

Dahlia. (2019). "Produktivitas Tenaga Kerja Pada Pekerjaan Pondasi Pasangan Batu Belah Di Beberapa Proyek Di Kota Balikpapan". Tugas Akhir (tidak dipublikasikan). Politeknik Negeri Balikpapan.

Hinze, J. W. (2008). "Construction Planning and Scheduling", 3rd Edition. Pearson.

Husen, A. (2009). "Manajemen Proyek: Perencanaan, penjadwalan dan pengendalian proyek". Andi.

Kedir, F., and Hall, D.M. (2021). "Resource Efficiency in Industrialized housing construction - A Systematic Review of Current Performance and Future
Opportunities". Journal of Cleaner.

Nuryanto, H., \& Winarno, S. (2021). "Kurva Belajar pada Pekerjaan Pondasi Dangkal yang Menggunakan Material Blok Beton". Simposium Nasional Teknologi Infrastruktur (SNTI) Abad 21, 231-236.

Olomalaiye, P. O., Jayawardane, A. K., \& Harris, F. C. (1998). "Contruction Productivity Management ", 1st edition. Prentice Hall.

Pramono, W. A., Winarno, S., \& Teguh, M. (2020). "Pengaruh Penambahan Sekam Padi sebagai Agregat Halus terhadap Karakteristik Batako". Civil Engineering Environmental and Disaster Risk Management Symposium, 360-366.

Ravianto, J. (1986). "Penelitian Kerja dan Produktivitas". Lembaga Pembinaan Manajemen.

Ryu, J., McFarland, T., Banting, B., Hass, C.T., Abdel-Rahman, E. (2020). "Health and Productivity Impact of Semiautomated Work Systems in Construction". Automation in Construction, 120, 103396.

Soekiman, A., Pribadi, K., Soemardi, B., Wirahadikusumah, \& R.D. (2011). "Study on Factors Affecting Project Level Productivity in Indonesia". Annals of Faculty Engineering Hunedoara- International Journal of Engineering 93, pp 35-40.

Wong, P., Cheung, S., \& Cliff Hartcastle. (2007). "Embodying Learning Effect in Performance Prediction". Journal of Construction Engineering and Management - ASCE, 474-482. 